Rev. Psicol. (Arequipa. Univ. Catól. San Pablo) / Año 2020 / Vol 10 / N 2 / pp. 81-91

ISSN 2306-0565 versión impresa / ISSN 2311-7397 versión on line

(c) $(\mathrm{P})\left(\bigodot_{\mathrm{BY}}\right.$

Esta obra está bajo una Licencia Creative Commons

Atribución 4.o Internacional (BY-NC-ND)

\title{
INICIOS DE LA PSICOLOGÍA OBJETIVA \\ EN EL INTERIOR DEL PERÚ (1910 y 1935)
}

\author{
BEGINNINGS OF OBJECTIVE PSYCHOLOGY \\ IN PERU (1910 AND 1935)
}

Arturo Orbegoso Galarza

Universidad César Vallejo, Trujillo, Perú

\begin{abstract}
Resumen
Este escrito trata sobre dos antecedentes pioneros en la psicología peruana. Las primeras pruebas de inteligencia aplicadas en el sur de este país entre 1910 y 1915 y la aparición de la psicología experimental en la norteña ciudad de Trujillo en 1936. Se destaca el contexto social y económico de cada experiencia y la actuación de sus protagonistas.
\end{abstract}

Palabras clave: Inteligencia, medición, experimentalismo.

\begin{abstract}
This article discusses two pioneering events in Peruvian psychology: the initial intelligence tests applied in the south of this country between 1910 and 1915 and the appearance of the first experimental psychology laboratory in the northern city of Trujillo in 1936. The social and economic context of each experience and the behavior of its protagonists is described.
\end{abstract}

Key words: Intelligence, measurement, experimentalism.

La historiografía sobre la psicología (2000) y León (1993), han sido replicados peruana se ha consolidado en los últimos en lo que va del siglo por otros investiaños. Lo que fueron esfuerzos originales gadores. Así, se ha profundizado en la y pioneros, principalmente de Alarcón vida y obra de algunos autores nativos y 
extranjeros que contribuyeron a desarrollar la psicología en el Perú (Arias, 2015; Caycho, 2013).

Pese a lo avanzado, cabe todavía cubrir algunos espacios poco o nada abordados. Uno de estos es la emergencia de la psicología en las regiones del interior del país. Contra la creencia común, que sostiene que la psicología objetiva aparece recién en los años '3o en la Universidad Mayor de San Marcos en Lima, hubo amagos de su aplicación y estudio en provincias. Pero esta empresa de reconstrucción no puede afrontarse sin algunos criterios o premisas que sirvan de guía o soporte explicativo.

Este texto propone la siguiente idea ya formulada anteriormente (Orbegoso, 2017, 2018). La psicología científica en el Perú nace con la modernidad capitalista que irrumpió a modo de vías férreas, minas y de una primitiva industrialización en algunas regiones de este país entre fines del siglo XIX y principios del XX. En concreto, hacia 1910, junto con el incremento del comercio lanar gracias a la prolongación del ferrocarril del Sur, se manifestó la necesidad de auscultar psicológicamentea escolares andinos y así determinar su real disposición para convertirse en sujetos de la emergente nueva realidad económica y social. En tanto que la agroindustria y la producción fabril en la costa norte, al dislocar el orden social tradicional, propiciarán la aparición de la psicología experimental en Trujillo en los años ' 30.

En este recuento se menciona a la Universidad San Antonio Abad del Cusco y a la Universidad Nacional de Trujillo. De ambas instituciones, inmersas en procesos de cambio social y económico en sus respectivas época y región, emanaron académicos claramente preocupados por aplicar la psicología moderna.

En las líneas siguientes se recrea primero el contexto que rodeó la aparición de la psicología en el sur andino. Luego se hace los propio con lo acecido en la costa norte peruana. Se concluye trazando semejanzas y diferencias entre ambos procesos.

\section{La psicología en el sur andino $(1910$ - 1915)}

\section{El plan educativo civilista}

Entre 1900 y 1910 el antiguo Partido Civil promueve hasta dos reformas de la instrucción pública. Sus ejes fueron centralizar las acciones relativas a este ámbito y extender la educación elemental gratuita. Con dicho objetivo se convocó educadores extranjeros para que capacitaran maestros provenientes de provincias. El centro de esta formación fue la Escuela Normal de Varones de Lima fundada para tal efecto. En poco tiempo algunos pedagogos foráneos y los primeros egresados normalistas asumieron cargos oficiales (directores, maestros e inspectores) en localidades del interior.

Hubo, de partida, cierto optimismo, como lo muestra el testimonio de un ministro de la época:

Felizmente está probado que no hay ninguna raza ineducable; no lo es la nuestra, por cierto, ni en las más remotas 
regiones territoriales. La leyenda de que el indio no quiere salir de su condición mísera, va desacreditándose rápidamente. (Polar, citado en Contreras \& Oliart, 2014, p. 18)

El proyecto educativo civilista buscó integrar a las poblaciones rurales por medio de la alfabetización y el establecimiento de escuelas en las capitales distritales (Contreras \& Oliart, 2014). Esta empresa suscitó en algunos educadores normalistas el interés por emplear pruebas psicológicas entre los niños de tales zonas (Orbegoso, 2016, 2018).

\section{Economía y sociedad rural}

A partir de 1890 se produce una serie de cambios en Arequipa con repercusiones en regiones vecinas (Contreras \& Cueto, 2008). La extensión del ferrocarril hacia Cusco y Punoy el auge de los precios de la lana de camélidos y del caucho de la selva multiplican los negocios: las minas (con capitales estadounidenses y británicos), las empresas de transporte, de construcción civil, agrícolas e industriales, además de curtiembres, fundiciones y molinos. La mano de obra comprendía también a artesanos, talladores, zapateros y panaderos (Flores Galindo, Plaza \& Oré, 1978).

En cuanto a Cusco, destacó por una producción variada y un naciente mercado urbano, incluso superiores a los de Arequipa. Como ésta, también contaba con fábricas textiles, de cerveza, molinos y hasta una hidroeléctrica, junto con pequeños negocios (Jacobsen, 1989). En torno a Puno, la lana fue uno de los pilares de su economía. Si bien carecía de industrias, el comercio lanar potenciado por el ferrocarril alimentó la aparición de tenderos, comerciantes y clases medias. Por si fuera poco, los precios del cauchoy del oro provocaron que los "enganchadores" reclutaran trabajadores de esta región y del vecino Cusco (Tamayo, 1980, 1982).

\section{Mediciones de la inteligencia en zonas rurales}

Las primeras pruebas psicológicas aplicadas a escolares peruanos se debieron al educador y abogado cusqueño Humberto Luna Pacheco (1887-1926) entre 1911 y 1912 mientras fue inspector de educación (Mac Knight, 1915a). Esto fue posible debido a varias circunstancias. De un lado, la evolución económica y social del sur andino contribuyó a ello: las escuelas distritales que reunían a menores de la zona fueron una ayuda evidente. A ello se sumó la mentalidad industrialista y moderna que iba difundiéndose entre la población urbana de dicha región. Sin olvidar la ampliación de las vías férreas que permitió vincular localidades antes incomunicadas.

En cuanto a las influencias recibidas por Luna, debe recordarse que fue egresado de la Normal capitalina en la que recibió nociones de psicología objetiva (Orbegoso, 2016). Asimismo, por aquellos días eran moneda común los estudios antropométricos. Además, Luna fue parte de aquella generación que encabezó la primera huelga estudiantil en la Universidad San Antonio Abad del Cusco en 1909. Gracias a que logró la atención 
de sus exigencias por parte del gobierno central se considera a este movimiento la primera reforma universitaria peruana del siglo XX. Este éxito, combinado con acentuados regionalismo e indigenismo, generaron una serie de estudios sobre la realidad económica y social cusqueña (Matos, Deustua \& Rénique, 1981).

Luna seleccionó a 30 niños de clase alta y clase baja, respectivamente. Su investigación se centró en determinar el grado de desarrollo de los procesos cognitivos de tales menores. Así describe su trabajo:

...las pocas [observaciones] que he practicado han sido con aparatos sencillos i experiencias elementales, relacionadas con la atención, percepción, memoria, asociación de ideas, imaginación, sentimiento, voluntad i lenguaje, concluyendo con un pequeño aparte acerca de los niños anormales. (Luna, citado por Giesecke, 2015, p. 266)

Años después, en otro de sus libros, Luna concluye que:

Las facultades mentales del niño indígena tienen un desarrollo más tardío, a consecuencia de la falta de educación en el hogar i en el medio social en que vive. La memoria, el raciocinio, la imaginación, etc. están muy poco ejercitadas constituyendo un poderoso obstáculo para la iniciación de las labores intelectuales en la escuela. Observa i contempla los fenómenos de la Naturaleza, sin que haya quien le pueda explicar el porqué de ellos. Sus acomodaciones mentales son, pues, elementales o rutinarias. (Luna, 1922, p. 228, cursivas en el original)

Como otros de su generación, Luna está convencido de que la educación es el mejor medio de redimir a los indígenas. No obstante esta aparente certeza, algunos estudiosos de la intelectualidad cusqueña del 900 creen identificar tras ella una actitud de superioridad, cierto paternalismo y un afán por distanciarse del sector campesino y pobre, a pesar del innegable origen étnico común (De la Cadena, 1997, 2004). En concreto, Luna y otros indigenistas reconocen que el indio puede ser alfabetizado e integrado parcialmente a la modernidad, pero los siglos de explotación colonial y republicana hacen muy difícil que asuma un rol destacado. Este papel estaría reservado a personas de familias tradicionalmente instruidas (Orbegoso, 2016, 2018).

Casi por la misma época en que Luna fue inspector de educación, el norteamericano Joseph Mac Knight (1872-1945) cumplió la misma función en el Altiplano (Puno). Invitado con otros educadores estadounidenses por el gobierno, su misión consistía en colaborar para que la reforma educativa se cumpliera aún en zonas apartadas.

Durante su periplo por las escuelas, Mac Knight aplicó una serie de pruebas que pretendían medir aptitudes como aritmética, percepción, memoria, raciocinio, antónimos y conocimientos prácticos. Como Luna, también realizó mediciones antropométricas. Evaluó a 800 escolares de Puno, Arequipa y Lima, ciudad ésta a la que volvió en 1911 para ocupar el cargo de 
Director de la Escuela Normal de Varones (Orbegoso, 2016, 2018).

En el informe que comunica su investigación, Mac Knight evidencia el prejuicio anglosajón hacia las poblaciones nativas del hemisferio sur, el mismo que se combinó muy bien con el de la clase dominante peruana:

No creo constituya motivo de alarma el hecho de que los niños blancos no hayan superado a los niños de raza india en todas las pruebas: la superioridad de los niños de raza blanca no peligra por este hecho, ni pone su superioridad indiscutida en tela de juicio. Como toda persona culta sabe, los niños de las llamadas razas inferiores pueden compararse sin gran desventaja con los de las razas superiores, tanto en su desarrollo físico como psíquico hasta cierta edad, diremos de los doce a los catorce años, pero después de esta edad los niños de las razas inferiores comienzan a decaer relativamente. La explicación de este fenómeno no es de difícil solución. Las razas superiores han pasado hace tiempo al través de ciertos períodos de su desarrollo, mientras que las otras razas están atravesando recién esas etapas o en el mejor de los casos, las han atravesado recientemente. (Mac Knight, 1915b, p. 288)

\section{La pérdida de interés}

Los trabajos de Luna y Mac Knight figuran hasta hoy como esfuerzos pioneros pero aislados. No se sabe de otras indagaciones posteriores a 1915. Como se recuerda, los estudios psicométricos resurgirán hacia los años '40 gracias a la presencia de Walter Blumenfeld (1882-1967) en la Universidad Mayor de San Marcos. ¿Pero qué hizo que estos intentos pioneros por aplicar la psicología moderna no tuvieran continuidad en las escuelas del sur andino? Para entenderlo, primero debemos recordar que se trató de mediciones psicológicas muy específicas. No había, en la intención de sus realizadores, objetivos más ambiciosos, por lo menos en la coyuntura examinada.

Deben apuntarse otras dos posibles razones para este hiato en la aplicación de pruebas psicológicas en el sur andino. Desde el punto de vista oligárquico y sus prejuicios inherentes, se les asumió como inconducentes debido a los pobres resultados obtenidos en estas primeras mediciones. Un ministro de la época sostuvo, a propósito de esto, que la "mayor parte de nuestra población está muy retardada, intelectualmente [,] (...) para esa población retardada se debe hacer solo la escuela elemental (citado en Ccahuana, 2013, p. 55). Adicionalmente, su interrupción también pudo causarla el fuerte influjo de la metafísica y de los irracionalismos que, como se sabe, negaban la posibilidad de objetivar lo subjetivo y dominaron en los ambientes académicos de la época (León, 1993; Orbegoso, 2016).

Contreras (en Contreras \& Oliart, 2014) examina el agotamiento de la reforma educativa civilista y su análisis puede ayudar a entender la fugacidad del interés por la psicología. De un lado, dicho plan fue una iniciativa autoritaria y centralista, implicó presionar a los habitantes rurales 
para que aceptaran la alfabetización de sus hijos. Es decir, fue una directiva de carácter vertical emanada desde la capital Lima. A la explicable resistencia de los campesinos, que percibían a los maestros como distantes socialmente, se añadió la desconfianza de los poderes locales: hacendados, alcaldes, prefectos y jueces. Estos reaccionaron negativamente ante los maestros pues eran una amenaza para sus parcelas de poder en sus respectivas regiones. Esto puede haber afectado el desempeño de los maestros, haciendo su actuación más discreta. Por otra parte, a partir de 1919, tras inaugurarse el llamado oncenio de Leguía, la administración de este presidente detuvo la reforma educativa en marcha y ésta perdió energía.

Debe recordarse que ya durante su gestión como director de la Escuela Normal de Varones de Lima Mac Knight había padecido la incomprensión, imposiciones y recortes presupuestales del gobierno central, lo que mermó la formación de maestros. Y en 1915 fue obligado a retirarse del país gracias a las maniobras de sectores conservadores que, debido a su credo protestante, lo consideraban un agente contrario a los valores católicos tradicionales y una influencia demasiado liberal y hasta anarquista para los normalistas (Encinas, 1932; Orbegoso, 2016). Esto, combinado con la prematura desaparición física de Luna, en 1926, contribuyó a que se diluyera la inicial atención prestada a las pruebas de inteligencia en el sur andino.

En 1928 la Normal limeña es desactivada y reemplazada por escuelas normales en el interior del país. Esta medida no hizo más que agravar la pérdida de calidad en la formación de maestros. Un elemento adicional, también recogido por Contreras (en Contreras \& Oliart, 2014) es la preferencia de cierto número de los primeros normalistas por emplearse en escuelas privadas. Esto permitió su desarrollo individual pero frustró el cambio en las escuelas públicas. De otro lado, la preocupación de los normalistas Luna y Mac Knight por la psicología se restringió a la aplicación de ésta en la educación y a la psicometría. No hay evidencia de exploraciones en la clínica, ámbito en el que carecían de formación y que en Lima concentraban los psiquiatras Valdizán y Delgado. Asimismo, desde 1925 la adaptación y aplicación de pruebas psicológicas fueron monopolizadas por el Seminario de Pedagogía que en la Facultad de Letras de la Universidad Mayor de San Marcos de Lima dirigía Luis Miró Quesada (1880-1976).

\section{La psicología en Trujillo (1935-1940)}

\section{Sociedad y universidad en proceso de cambio}

La región La Libertad era desde el último tercio del siglo XIX centro de las principales haciendas azucareras y por ello congregaba a un significativo contingente de peones agrarios y pequeños labriegos independientes. El auge de la producción latifundista fue el elemento dinamizador de la economía liberteña. Este crecimiento relativamente constante atrajo migrantes de zonas andinas y generó la emergencia de pequeños comerciantes, artesanos, intelectuales y empleados. Estos 
segmentos fueron el público natural de la prédica política, anarquista primero y aprista después (Gonzales, 2016).

La industria azucarera transformó radicalmente la ciudad de Trujillo, capital de La Libertad. Su impacto causó la ruina de otras actividades. Muestra de ello fue que los bazares de las haciendas hicieron quebrar a los comerciantes locales. Un segmento significativo de su población decayó y se convirtió en masa asalariada (Basadre, 2005). Otras ocupaciones dependían también de los requerimientos de las haciendas, como artesanos, maestros y médicos. El historiador Klarén (1976) sostiene que una respuesta al sometimiento que padecían amplios sectores de la sociedad fue el radicalismo de los intelectuales trujillanos. Lo avasallador del capitalismo fortaleció sus ideas de izquierda (Klarén, 1976).

Hacia mediados de la década de 1930 persistían en la Universidad Nacional de Trujillo los reclamos por una reforma universitaria. Aún estaba muy vivo el recuerdo de la sublevación de 1932 y su violento sometimiento por las fuerzas armadas. Tal vez como una forma de conjurar esa inquietud remanente, las autoridades universitarias ejecutan una serie de cambios. Esto último habría sido imposible sin la aquiescencia y el apoyo económico del gobierno central. Así lo explica una fuente:

En la década de 1930, aparecieron nuevos actores sociales, como las organizaciones de trabajadores y los partidos políticos de masas, entre otros, que influyeron en las políticas sociales. (...) Los gobiernos militares de Sánchez Cerro y Benavides, vinculados con las élites, (...) tuvieron que implementar políticas redistributivas y de control social para mantener el orden público. (Parodi, en Contreras, 2014, p. 422)

Efectivamente, por esos años hubo una paulatina recuperación de los precios de las materias primas luego de la Gran Depresión, lo que permitió un intermitente aumento del gasto en salud, vialidad y educación (Contreras, 2014).

\section{La psicología en la UNT: alcance y limitaciones}

A partir de 1935 en la UNT se crean nuevas carreras, se contrata docentes del exterior y se habilitan los laboratorios indispensables para la mejor formación de su alumnado. Dentro de estos cambios sobresale la creación de la sección o carrera de Pedagogía. Su plan de estudios contempló una asignatura de psicología experimental. Para impartirla se convoca primero al belga Isidore Poiry (1868-1954), otrora primer director de la Normal de Lima. Este declina y recomienda al alemán Hans Hahn (1900-1969), psicólogo alemán y judío, por entonces refugiado en Bélgica (Orbegoso, 2016).

La evidencia escrita prueba que la UNT cumplió con adquirir del extranjero equipos para un laboratorio o gabinete de psicología experimental que fue regentado por Hahn como responsable del curso 
homónimo desde su arribo a Trujillo en julio de 1937 (Orbegoso, 2016).

Si bien la inclusión de la psicología experimental como materia obligatoria así como el establecimiento de su respectivo laboratorio en la Universidad de Trujillo rompieron con una larga tradición de la psicología como disciplina filosófica, la gestión de Hahn al frente de estas innovaciones fue breve, de apenas dos años. La correspondencia oficial de 1939 refiere que su trabajo no estuvo a la altura de lo esperado por las autoridades y los estudiantes. Se alude a sus características de personalidad, la diferencia idiomática y una particular noción de la psicología científica (Orbegoso, 2016)

La psicología en la UNT aparece como un reflejo más de los cambios que atravesaba la sociedad liberteña y en concreto la ciudad de Trujillo. La necesidad de brindar opciones a una población trastocada por la absorbente y omnímoda industria azucarera, además de ideas políticas que periódicamente se convertían en agitación. La continua migración de la sierra y el crecimiento de sectores medios e intelectuales conducen a que se extienda la oferta universitaria.

Tras los sucesos descritos la psicología en esta región no tuvo mayor trascendencia. Puede especularse acerca de que tal vez las autoridades universitarias no quisieron o no supieron potenciar esta disciplina y consideraron que lo logrado, una asignatura y un laboratorio experimental, eran suficientes para los estudiantes de pedagogía. Igualmente, puede argüirse que desde mediados de los 30 el centro de la psicología experimental en el Perú estaba en la Universidad Mayor de San Marcos de Lima, gracias a los trabajos del ya citado Blumenfeld. Fue él quien concentró la docencia y la investigación en dicho campo hasta los años ' 60 inclusive. Es más, hasta el propio Hahn parece que lo comprendió así. Luego de dejar la UNT ingresó como docente en la universidad limeña (Orbegoso, 2016).

\section{Paralelo y deslinde}

Las dos experiencias reseñadas tienen como telón de fondo común transformaciones en sus respectivas regiones. El orden tradicional sufrió modificaciones y emergieron nuevos segmentos producto de la dinámica económica. Académicos de dos universidades, la cusqueña y la trujillana mediaron en este proceso e hicieron posible la aparición de la psicología. Se acogió a esta ciencia como una necesidad, tanto para establecer perfiles cognitivos de escolares andinos, como para mostrar las constantes psicológicas generales a los estudiantes de pedagogía trujillanos.

Entre las diferencias de ambos procesos destaca en primer lugar la de tiempo y lugar. Mientras que en el Sur la semi-feudalidad no se alteró, los emergentes reductos de modernidad (ferrocarril, comercio, universidad) explican las iniciativas por realizar mediciones psicológicas. En el Norte, por su parte, los 
latifundistas optaron por industrializar su producción, lo que acarreó un cambio más profundo (proletarización y actividad política). Así explica esta disparidad entre ambas regiones un célebre estudio:

La oligarquía norteña se vio empujada a recolectar mano de obra para sus haciendas y a iniciar un proceso de transformación en los aspectos técnicos de la producción del azúcar, en orden de mantenerse competitivamente en el mercado mundial Los oligarcas sureños no tuvieron necesidad de introducir mejoras técnicas en los sistemas de crianza del ganado, ni en el cultivo de pasto, ni en el cercado de terrenos ni de asalariar a los productos (sic) directos, sino recién pasada la década del veinte del presente siglo. Su poder se estableció, sobre la base del monopolio del comercio de lanas, y sobre una complicada red de alianzas con los gamonales y las autoridades locales. (Flores Galindo, Plaza \& Oré, 1978, p. 72)

Finalmente, en cuanto a las tempranas mediciones de Luna y Mac Knight en el sur peruano, queda claro que su noción de la psicología estuvo en gran medida gobernada por la psicometría, vertiente muy fuerte en aquellos años. Tales evaluaciones permitieron a sus ejecutores justificar la estructura social imperante, incluyendo la secular exclusión de los habitantes andinos. Sobre la psicología experimental en Trujillo hay que agregar, para concluir, que fue un rasgo distintivo de la mentalidad moderna o industrialista que se extendió por dicha región y que buscó actualizar la formación de sus maestros. 


\section{Referencias}

Alarcón, R. (2000). Historia de la psicología en el Perú. Lima: Universidad Ricardo Palma.

Arias, W. L. (2015). Honorio Delgado (1892-1969), un repaso histórico sobre su vida y obra: A propósito de los 100 años del psicoanálisis en el Perú. Boletín de la Academia Paulista de Psicología, 35(89), 286-308.

Basadre, J. (2005). Historia de la República. Lima: El Comercio.

Caycho, T. (2013). Walter Blumenfeld: Vida y obra de un pionero en el desarrollo de la psicología científica en el Perú. Eureka, 10(2), 216-229.

Ccahuana, J. (2013). “Según la capacidad intelectual de cada uno”: Élites, estado y educación indígena a inicios del siglo XX. (Tesis de Licenciatura en Historia). Pontificia Universidad Católica del Perú, Lima, Perú.

Contreras, C. (Ed.) (2014). Compendio de historia económica V: la economía peruana entre la gran depresión y el reformismo militar, 1930-1980. Lima: Banco Central de Reserva del Perú - Instituto de Estudios Peruanos.

Contreras, C., \& Cueto, M. (2008). Caminos, ciencia y Estado en el Perú, 1850-1930. História, Ciências, Saúde, 15(3), 635-655.

Contreras, C., \& Oliart, P. (2014). Modernidad y educación en el Perú. Lima: Ministerio de Cultura.

De la Cadena, M. (1997). La decencia y el respeto: raza y etnicidad entre los intelectuales y las mestizas cuzqueñas. Lima: Instituto de Estudios Peruanos.

De la Cadena, M. (2004). Indígenas mestizos: raza y cultura en el Cusco. Lima: Instituto de Estudios Peruanos.

Encinas, J. (1932). Un ensayo de escuela nueva en el Perú. Lima: Imprenta Minerva.

Flores Galindo, A., Plaza, O. \& Oré, M. (1978). Oligarquía y capital comercial en el sur peruano. Debates En Sociología, 3, 53-75.

Giesecke, M. (2015). Política educativa y ruralidad en el Perú: 1900 a 1930. (Tesis para optar el grado de doctor en Ciencias Sociales). Universidad Nacional Mayor de San Marcos, Lima, Perú. 
Gonzales, M. (2016). Azúcar y trabajo. La trasformación de las haciendas en el norte del Perú (1860-1933). Lima: Banco Central de Reserva del Perú - Instituto de Estudios Peruanos.

Jacobsen, N. (1989). Libre comercio, élites regionales y mercado interno en el sur del Perú, 1895-1932. Estudios y Debates, 2, 409-449.

Klarén, P. (1976). Formación de las haciendas azucareras y orígenes del APRA. Lima: Instituto de Estudios Peruanos.

León, R. (1993). Contribuciones a la historia de la psicología en el Perú. Lima:CONCYTEC.

Luna. H. (1922). Metodología pedagógica para la enseñanza primaria. Cuzco: Tipografía y Librería "Cuzco".

Matos, J., Deustua, J., \& Rénique, J. (Eds.) (1981). Luis E. Valcárcel. Memorias. Lima: Instituto de Estudios Peruanos.

Mac Knight, J. (1915a). Caracteres físicos y mentales del niño peruano. La Escuela Moderna, 5(11), 203-216.

Mac Knight, J. (1915b). Caracteres físicos y mentales del niño peruano. La Escuela Moderna, 5(12), 256-299.

Orbegoso, A. (2016). Psicología peruana. Los prejuicios detrás de la ciencia. Trujillo: Universidad César Vallejo.

Orbegoso, A. (2017). Hacia una historia social de la psicología peruana. Revista de Psicología (Universidad Católica San Pablo), 7(2), 99-112.

Orbegoso, A. (2018). Orígenes sociales de la psicología y la psiquiatría en el Perú (18501930). Lima: Sociedad Peruana de Historia de la Psicología.

Tamayo, J. (1980). Historia del indigenismo cusqueño. Siglos XVI-XX. Lima, Perú: Instituto Nacional de Cultura.

Tamayo, J. (1982). Historia social e indigenismo en el Altiplano. Lima: Ediciones Treintaitrés.

Recibido: 16 de junio del 2020

Aceptado: 12 de julio del 2020 